\title{
Repair of Massive and Irreparable Rotator Cuff Tear Using Arthroscopic Method
}

\author{
Ardeshir Alidousti', Fateme Mirzaee ${ }^{2}$, Fateme Bahramian², Zohreh Zafarani ${ }^{2}$, Naeeme Mirzaei ${ }^{3}$, Hamidreza \\ Aslani $^{*}$ \\ 'Islamic Azad University of Medical Sciences Qeshm Knee and Sport Medicine Research and Education Center, Milad \\ Hospital, Tehran, Iran \\ ${ }^{2}$ Knee and Sport Medicine Research and Education Center, Milad hospital, Tehran, Iran \\ ${ }^{3}$ Islamic Azad University of Medical Sciences Tehran, Knee and Sport Medicine Research and Education Center, Milad \\ Hospital, Tehran, Iran
}

\section{*Correspondence to Hamidreza Aslani, Shahid Beheshti University of Medical Sciences, Knee and Sport Medicine Education and Research Center, Tehran, Iran. Tel/Fax: +98-2188621147; Email: hraslani1342@gmail.com}

Published online 28 July 2018

\section{Introduction}

Shoulder pain is one of the complaints of patients refering to office based physicians and sports medicine doctors. The spread of shoulder discomfort has been reported to be $16 \%$ to $34 \% .{ }^{1}$ The most common cause of chronic shoulder pain is over-employment-induced damages. Shoulder impingement syndrome is the most common problem with a prevalence of $24 \%-65 \%$, which is seen in many overhead movements, sports activities, daily life and/or jobs. ${ }^{2}$ The prevalence of rotator cuff-induced injuries has been observed to be higher in swimming, tennis, volleyball, skiing, and wrestling. To treat such injuries, various therapies such as prescription of oral and muscle anti-inflammatory corticosteroids, jointinfiltration through subacromial injection, ice treatment in acute post-injury cases, friction-type massage, injured organ immobilization, stretching and strengthening exercises, movement therapy, ultrasound, and stimulation of electrical nerve transfers are used. The aim of these therapies is to reduce pain, restore one's range of natural motion and return one to one's normal life. ${ }^{3}$ The rotator cuff is the only periarticular structure in the body which can be repaired by a variety of open and arthroscopic surgical procedures, and in case this organ becomes defective, some disabilities occur which may require to perform arthroplasty. ${ }^{4}$ Fortunately, with advances in surgical techniques and relevant tools, the majority of rotator cuff tears including massive ones can be repaired. ${ }^{5}$ So they are recommended for early rotator cuff repair, even for massive rotator cuff. ${ }^{6}$ The difference regarding massive and irreparable rotator cuff tear (IRCT) is very important, since, not all massive tears are in irreversible form. ${ }^{7}$ As IRCT implies, this type of tear refers to tears in which rotator cuff space on larger lump over the humerus cannot be compensated, or according to Gerber et al, any successful repair almost certainly ends in a structural

Please cite this article as follows: Alidousti A, Mirzaee F, Bahramian F, Zafarani Z, Mirzaei N, Aslani H. Repair of massive and irreparable rotator cuff tear using arthroscopic method. J Lasers Med Sci. 2018;9(3):168-176. doi:10.15171/jlms.2018.31. 
failure. ${ }^{8}$ Treatment of IRCT patients without arthritis is one of the most challenging problems for orthopedic surgeons. Recently, reverse shoulder joint arthroplasty is considered for patients that have or do not have glenohumeral arthritis in the presence of IRCT., ${ }^{9,10}$ Although the initial mid-term results were promising, long-term outcomes are still ambiguous. ${ }^{8}$ Moreover, complications have been various on patients, ranging from $4.3 \%-50 \%$ with a $10 \%$ rate of revision. ${ }^{11}$ Tendon transfer is an alternative treatment in younger IRCT patients without arthritis. ${ }^{7}$ The purpose of this study is to address the challenges facing professionals in choosing the best treatment for rotator cuff tear. According to the results of some studies, a range of rotator cuff treatment techniques have been a hot topic with a focus on arthroscopic treatment.

\section{Methods}

Search Strategy

Population Intervention Comparison Outcome (PICO) was the search plan, which comprised all articles published during 1990 to 2016 (Table 1).

The search was achieved in the databases of Science Direct, PubMed, Medline, Embase, Iranmedex, and Medlib using OR, AND, and NOT between the selected keywords (Arthroscopy, massive rotator cuff, irreparable) to find relevant articles. Finally, 85 articles were selected.

\section{Results}

Open Surgery and Arthroscopy

Historically, open surgery has been the leading surgical procedure for the treatment of massive rotator cuff tear. Recently, with the development of new tools and surgical experiences, arthroscopic repair is widely accepted in society. ${ }^{12,13}$ Complete care of massive rotator cuff tears continues to remain a challenge in shoulder surgery. Therapeutic options have changed compared to traditional treatment methods in open surgical or arthroscopic debridement with or without decompression. ${ }^{14}$ Today, the desire to use arthroscopy-based repair is gradually increasing. The type of treatment depends on the patient's age, activity level, type and extent of the tear. Debridement and decompression are recommended in massive irreparable tears. ${ }^{5}$ Most signs of rotator cuff tear can be successfully controlled by the arthroscopic method. In case of massive rotator cuff tears, anatomical repair could be beneficial when provided by increased mobility followed sufficient rotator cuff release. However, poor quality of cuff muscle caused by severe tendon pulled back of head tendons and severe contraction by fat degeneration may increase the risk of recurrent tear in the repaired areas. ${ }^{15}$ The advantages of arthroscopy techniques compared to open procedures of the shoulder joint stabilization include smaller skin incisions, more complete glenohumeral joint assessment, intra-articular injury repair, access to all intra-articular areas to repair injuries, less soft tissue damage, maintaining maximum external rotation of arms and simultaneous diagnosis and treatment of other intra-articular pathology such as SLAP. ${ }^{16}$ In general, length of stay and post-operation pain are lower in the arthroscopic method and better cosmetic results can be achieved. ${ }^{17}$ On the other hand, in open procedures, motion limitation and decreased function are more common. The disadvantages of arthroscopic procedures consist of the length of the learning curve as well as more dislocation relapse compared to open procedures. ${ }^{18}$ While the closing decision on rotator cuff repair is built during surgery, the signs and symptoms as well as radiological findings before surgery help surgeons to make a better decision on the type of treatment and restoration. Classically, patients will present with pain and physical disability; however, these symptoms are directly related to the size or tear repair. Clinical symptoms that indicate successful improbable recovery include partial dislocation of anterior-superior static and pseudoparalysis of the anterior parts. ${ }^{8}$ The anterior dislocation associated with a dynamic partial tear of the proximal humerus resist against being away from the axis of the body. Furthermore, symptoms of slowness and hornblower's act as symptoms with poor diagnostic prognosis. ${ }^{19}$ We have no knowledge of randomized controlled trials comparing surgical treatments with non-surgical treatments. Moreover, patients with massive rotator cuff tear are considerably heterogeneous with respect to the severity of the tear, texture quality, symptoms, and

Table 1. Selected Keywords Used in This Study Based on PICO

\begin{tabular}{|c|c|c|c|}
\hline Outcome & Comparison & Intervention & Population \\
\hline $\begin{array}{l}\text { Pain } \\
\text { Function } \\
\text { Weakness } \\
\text { Strength } \\
\text { Active motion } \\
\text { Rang of motion }\end{array}$ & No & $\begin{array}{l}\text { Reverse shoulder arthroplasty } \\
\text { Tuberoplasty } \\
\text { Graft Interposition } \\
\text { Suprascapular nerve ablation } \\
\text { Hemiarthroplasty (hemi joint replacement) } \\
\text { Partial rotator cuff repair } \\
\text { Complete repair } \\
\text { Debridement with or without a bicep tenotomy } \\
\text { Interval slide } \\
\text { Arthroscopic superior capsular repair }\end{array}$ & Individuals with massive rotator cuff tears \\
\hline
\end{tabular}


functional compromise (Table 2). ${ }^{20}$

Non-surgical Treatments

Some investigators have been suggesting that the repair of massive rotator cuff tears occurs after a high inhibiting relapse rate and that it may be treated by non-surgical treatments or simple debridement. Some reports have revealed that patients with massive tear are able to move and perform their daily activities. Non-surgical control of the massive rotator cuff tear is typically assigned to patients who have significant pain. ${ }^{21}$ Improved performance may be achieved by changing tasks, proper use of steroid injections and physical therapy with an emphasis on the anterior deltoid exercises. Other therapeutic targets include rehabilitation of muscle, muscle contraction coordination, pre-scapular strengthening, maintaining movement and improving proprioception. Furthermore, patients should also implement the guidelines on longterm techniques to avoid excessive stress on the shoulders. As Ainsworth studied 10 patients with massive rotator cuff tear, who were treated according to the protocol, she observed that they significantly improved according to estimates provided by the Oxford Shoulder Disability Association as well as assessments of 36 items associated with Health Association. ${ }^{21}$ Although joint deterioration was observed, these patients did not show any significant change in their active movement and they were able to maintain a satisfactory shoulder performance according to the constant score. ${ }^{14}$ It seems that the non-surgical treatment method has fewer consequences for patients who have chronic shoulder diseases. The result of a study conducted by Bokor et al on 53 patients with the entire thickness rupture after non-surgical treatment, showed that the group of patients who had the disease symptoms for more than 6 years, compared with those who had started recently. ${ }^{22}$
Various Treatment Methods for Massive and Irreparable Rotator Cuff Tear

Repair of large and extensive rotator cuff tear has been difficult. Arthroscopic repair of rotator cuff is used for minor tears and complete tear that are small-to-mediumsized (smaller than $3 \mathrm{~cm})^{23}$ and open repair of rotator cuff is used for tears larger than 3 to 5 centimeters and massive tears (over $5 \mathrm{~cm}$ ) which are in the form of complete tears. In this type of tear, closure of muscular construction defects is not allowed in some cases despite great efforts due to the tendon pull back and replacement of adipose tissue in muscles. A common perception is that the remaining structure defects are directly associated with unsuccessful results. Therefore, several closure methods such as subscapularis tendon transfer to cover lesions in upper tendons, ${ }^{24}$ using fascia tissue in the form of allograft or auto graft, ${ }^{25}$ repair in a place more internal than the site of normal tendon junction, ${ }^{26}$ latissimus dorsi tendon transfer, ${ }^{27}$ transfer of debridement or free tendon and simple rotator cuff decompression ${ }^{28}$ have been developed. The outcomes of reports on arthroscopic repair of massive rotator cuff tears such as Chung et al reported the amount of anatomy loss to be $39.8 \%$, although there was a clinically significant improvement. ${ }^{5}$ Rockwood et al first used debridement and decompression methods to remove any factor that leads to entanglement in subacromial space in order to treat massive and IRCT. Their method consisted of acromioplasty, removing coracoacromial ligaments, and exchange of torn tendons necrotic debris. In 6-year follow-up study performed for 58 patients, the majority of patients improved in terms of pain and range of motion. ${ }^{29}$ Montgomery et al in a retrospective study compared the results of debridement repair for massive tear with restored treatment ${ }^{30}$ and better results were observed for the restored group. These findings were also confirmed in the long-term (6-9 years) with

Table 2. Studies Investigating Repair of Massive and Irreparable Rotator Cuff Tear Using Arthroscopic Method

\begin{tabular}{|c|c|c|c|}
\hline Authors & Method & Outcome & Result \\
\hline Bishop et al & Open surgery and arthroscopic & $\begin{array}{l}\text { Strength of elevation. External } \\
\text { rotation. }\end{array}$ & $\begin{array}{l}\text { ASES and ER increase. Constant, pain and } \\
\text { FE decrease. }\end{array}$ \\
\hline Lee et al & Arthroscopic tuberoplasty & $\begin{array}{l}\text { The University of California, Los } \\
\text { Angeles score. }\end{array}$ & $\begin{array}{l}\text { Active forward flexion increase. Pain } \\
\text { decrease. }\end{array}$ \\
\hline Zingg et al & Nonoperative & $\begin{array}{l}\text { Forward flexion, abduction, } \\
\text { external rotation, internal } \\
\text { rotation. }\end{array}$ & $\begin{array}{l}\text { The active range of motion did not change } \\
\text { over time. }\end{array}$ \\
\hline Williams & Operative (surgery). & Pain. Function. & Pain relief and improved function. \\
\hline Gartsman et al & Arthroscopic. & ASES, UCLA. & Improve UCLA and ASES. \\
\hline Cole and Romeo & Arthroscopic & Stability & $\begin{array}{l}\text { Outcomes should approximate or exceed } \\
\text { traditional open stabilization techniques. }\end{array}$ \\
\hline Liu and Henry & Arthroscopic & Side effect & Decrease side effect \\
\hline Gerberet al & Nonoperative and opertive & Pain, disability & Decrease pain, disability \\
\hline Walch et al & Operative & External rotation, abduction. & Improve external rotation and abduction. \\
\hline
\end{tabular}


$86 \%$ of restored patients versus $8 \%$ of debrided patients achieving satisfactory results and 23 patients out of 25 subjects in the debridement group requiring re-surgery. ${ }^{31}$ These findings showed that the initial favorable results of debridement compared with restored repairs lowers over time. Aforementioned symptoms and signs should be studied as part of therapeutic algorithms and contain simple debridement with or without tenotomy, partial rotator cuff repair with or without distance, tuboplasty, transplant in the form of rotator cuff interleaving, Suprascapular nerve ablation, reconstruction of the upper capsule and inserting biodegradable distance maker. This section introduces available arthroscopic techniques for rotator cuff tear. These include all recent and old innovative methods addressing the challenges of clinical problems.

\section{Debridement With or Without a Bicep Tenotomy}

The removal of dead tissues of the rotator cuff (debridement) and subacromial decompression was initially suggested by Rockwood et al in 1995 to treat patients with IRCT. In this short-term treatment method, satisfactory results were reported for patients with massive rotator cuff tears. ${ }^{32}$ This treatment method was mainly prescribed for the elderly and low demand patients suffering from pain. Following this treatment, the mean motion angle increased from 105 degrees to 140 degrees. ${ }^{29}$ Although there was no complete repair for shoulder strain after using this type of intervention, the shoulder performance was usually increased following the decreased pain caused by a blow in the accident. Then, Kempf et al presented an important improvement in pain followed by bicep tenotomy. ${ }^{8}$ In the absence of the rotator cuff tendon, bicep tendon may act to lower the end of the arms. Thus, the release of the long bicep tendon by surgery in patients with massive rotator cuff tear may lead to the displacement of the proximal at the end of the arm muscle. ${ }^{33}$ In most studies, it is shown that the bicep muscle is retractor against static and dynamic performance of the end of the arm and fixes the shoulder. ${ }^{34}$ EMG studies have revealed that the long end of the biceps in patients with massive rotator cuff tears is passive in taking the arm away from the body, indicating that its role in stabilizing is more probable in the inactive mode than the active one. This evidence indicates that the long end of the bicep tendon may be a major cause of pain and contributes to the pain related to marked massive rotator cuff tear symptoms. ${ }^{35,36}$

\section{Partial Rotator Cuff Repair}

For the first time in 1993, Burkhart et al presented the biomechanical idea of "suspension bridge" in the rotator cuff. This theory was also expanded to the rotator cuff and offered a rationale for rotator cuff repair. It involves the reconstruction of shoulder ropes involved in the transmission of power and forces around the shoulder.
Most irreparable tears have a degree of anterior and posterior stretch affecting cruciate and lateral pairs. ${ }^{37}$ Patients who enjoy this type of treatment have clinically a kind of imbalance in subscapular and infraspinatus performance. Burkhart's main article showed that there were improvements in various parameters such as the promotion of activity (promoting from 59.6 degrees to 150.4 degrees), stretch (rated from zero to 5) (promoting from 2.1 to 4.4 ) and UCLA scores (promoting from 9.8 to 27.6) (37). In another study, Berth et al compared partial arthroscopic repair of rotator cuff and debridement. Both treatment methods reflected similar developments; however, several other studies suggested that partial repair treatment compared to debridement follows a more sustainable improvement. ${ }^{38,39}$

\section{Complete Repair}

Achieving long-term treatment with a perfect structural repair is often difficult even if direct repair of a tendon in the bone is obtainable. These treatments often have had undesirable treatment and repair has been technically difficult. ${ }^{40}$ Despite the recovery and progress of working outcome, Galatz et al reported the return of tear in 17 individuals out of 18 patients which were under treatment for an average of 36 months after arthroscopic rotator cuff tear of above $2 \mathrm{~cm} .{ }^{41}$ The loss of tendon, muscle contraction and stretching as well as scarring after surgery are common and should be considered in order to attain acceptable repair of massive rotator cuff tear. Nevertheless, of rotator cuff repair being arthroscopic or open, the joints of subacromial and subdeltoid must be released and in order to enhance the clarity of pattern around the rotator cuff tear, bursal tissue (purity bag) must be removed. ${ }^{42}$ Surface joints of supraspinatus and infraspinatus muscles should slowly be released. ${ }^{43}$ Sometimes, the release of cover and capsule may also be required in order to have tendons without motion and contracting in massive tears. Jost et al discovered that the clinical consequences for patients in exchange for a repeated tear occurred following the rotator cuff repair were meaningfully related with the size of the returned defects and the extent of fatty infraspinatus and supraspinatus muscle transubstantiation. ${ }^{44}$ Infiltration is referred to as the fat around the muscles involved in the rotator cuff, as an adverse prognosis factor for repairing massive rotator cuff tears and post-repair consequences. Warner et al investigated patients with massive rotator cuff tear and found a relationship between the appearance of fat infiltration and the shoulder general biomechanics and MRI images and its performance. ${ }^{45,46}$ A relationship was observed between the severity of fat infiltration and inadequate tendon-tissue qualities during surgery. Moreover, pennation angle (average angle formed between the lines of muscle fibers and muscle function) decreases and the total fat in the space between the muscle fibers in chronic rotator cuff tear increases. ${ }^{47}$ 
Interval Slide

Melillo et al proposed the arthroscopic interval slide technique. $^{39}$ Then, this technique as an open surgical procedure was originally described by Bigliani et al. This technique involves the release of supraspinatus tendon by the rotator to improve mobility. ${ }^{48}$ Then, Lo and Burkhart reintroduced this technique as an anterior slide interval and described posterior slide interval as a secondary slide interval among supraspinatus and infraspinatus tendons. ${ }^{49}$ Concerns about this technique include loss and secularization of the supraspinatus tendon and loss of muscle tendon unit performance which was defective earlier. ${ }^{50}$

\section{Tuberoplasty}

Tuberoplasty as an alternative acromioplastic method for decompressing subacromial space. The concept of tuberoplasty as a new open surgical procedure was first developed in 2002 by Fenlin for the acromiohumeral joint. ${ }^{51}$ In this technique, tuberosities and larger bony appendages are transformed to form a smooth surface and a similar joint in larger tuberosity of the humerus and low level of scapula. In the first study, UCLA score increased from 9.3 to 27.7 with a $95 \%$ satisfaction level. ${ }^{51}$ Certainly, an arthroscopic tactic to this method was adopted in 2004 by Scheibel et al, described as a reverse arthroscopic acromial decompression method. ${ }^{52}$ In this study, the mean constant score enhanced from $65.9 \%$ to $90.6 \%$, accompanied with significant improvement in pain and improved range of motion and daily activities. ${ }^{52}$ Then, many studies following this study were issued approving the aids of arthroscopic tuberoplasty with or without acromioplasty as a treatment possibility in patients with IRCT. The studies revealed a significant improvement in terms of range of motion and reduced pain following surgery. ${ }^{13}$ In another study, Park et al in 2016 investigated the arthroscopic tuberoplasty and obtained satisfactory results over an 8-year follow-up period. Although the displacement of the upper end of the arm enhances over time, clinical results are not affected. According to the results of this study, arthroscopic tuberoplasty is a viable option for relieving pain and improving function in patients with no false paralysis compared with patients with massive rotator cuff tear. ${ }^{53}$

\section{Graft Interposition}

It was first presented in 1978 by Neviaser et al on IRCT patients considering dry-frozen rotator cuff allograft to repair the joint between contracted tendons of the rotator cuff and large tuberosities in patients. ${ }^{54}$ Although no standard scoring system was employed, a majority of patients showed excellent results in terms of analgesic effects. These results were reported during previous decades by Nasca following the use of the same techniques. ${ }^{55}$ There are variations of biological and synthetic grafts recommended. Used biological grafts include rotator cuff allografts, ${ }^{56}$ the quadriceps muscle tendon, ${ }^{57}$ knee tendon, ${ }^{57}$
Achilles tendon ${ }^{57}$ and Fascia tensor ${ }^{58}$ ) as well as dry-frozen autografts such as bicep tendon ${ }^{59}$ and Fascia tensor. ${ }^{60}$ In this technique, xenograft was also used for interposition, including swine dermal collagen and swine small intestine submucosal. ${ }^{61,62}$ The artificial grafts that were tested in the research included polyester ligament (Docron), ${ }^{63}$ a piece of Gore-Tex soft tissue ${ }^{64}$ and carbon fiber components. ${ }^{65}$ Mechanical properties of allografts have shown that they are of lower quality in comparison with autografts and artificial and synthetic grafts. ${ }^{66}$

\section{Suprascapular Nerve Ablation}

Suprascapular nerve (SSN) is originated from upper torso of upper neural network and is a combination of motor and sensory nerves. This nerve creates the main sensory nerving associated with posterior shoulder capsule, acromioclavicular Joint, subacromial holes, acromioclavicular ligaments (collarbone-crow) and coracohumeral ligaments. ${ }^{67}$ In various studies, blocking SSN has been proven to be beneficial for reducing chronic pain. In irreparable rotator cuff, blocking SSN is regarded as a treatment method. Patients are often considered for denervation who did not receive any improvement using other previous treatment methods. ${ }^{68}$ Among different techniques described in other studies, SSN radio waves and arthroscopic technique for SSN can be noted. Radio waves techniques are mainly described to treat chronic back pain. ${ }^{69}$ The theoretical benefit of this technique is that this procedure mostly affects smaller pain fibers than larger motor fibers and so, preserves function of the remaining motor neurons. Since the initiation, radio waves are used in a range of clinical conditions comprising their use on suprascapular neurons as an effective subcutaneous technique. ${ }^{70}$ More than $75 \%$ of the patients reported reduced pain and almost $80 \%$ of them noted improvement in their quality of life. Nevertheless, no assessment and discussion have yet been provided on the results of lack of residual infraspinatus activity. ${ }^{71}$

\section{Arthroscopic Superior Capsular Repair}

Glenohumeral joint superior capsule expanded in the lower surface of supraspinatus and infraspinatus tendons and attached to the rotator cuff plays an important part in creating joint superior stability. ${ }^{72}$ Rotator cuff tears are related to the superior cuff defect. Recently, Mihata et al have developed an arthroscopic technique for superior capsular reconstruction in patients with rotator cuff tears in order to prevent displacement of the upper end of the arm following accidents. ${ }^{73}$ Though, this technique is obtainable as an arthroscopic technique, however, it can also be done through the open surgery technique if preferred by surgeons.

\section{Hemiarthroplasty (Hemi Joint Replacement)}

Neer et al described rotator cuff hemiarthroplasty as the upper dislocation of the end of the arm, reduced 
acromiohumeral distance along with acromion stabilization (tip of the shoulder) and related to surface cover of the upper part of the end of the arm and high tuberosity. ${ }^{74}$ Hemiarthroplasty is a treatment option for patients with symptoms of rotator cuff arthropathy and low functional goals. ${ }^{75}$ Clinical reported outcomes are different for rotator cuff arthropathy after hemiarthroplasty. In this procedure, a surgeon may only replace ball and socket joint based on the shoulder problem, which is called hemi joint replacement or hemiarthroplasty. In surface reconstructing hemiarthroplasty, only the joint surface of the humeral head is replaced by cap-like prosthetic with no bars. Sanchez-Sotelo et al reported on 33 patients with glenohumeral arthritis and massive rotator cuff tear who underwent hemiarthroplasty. ${ }^{75}$ In their study, while the average pain was reduced from the preoperative value of 4.2 to 2.2 during final follow-up in a 5-year period, 9 patients had moderate pain at rest or during activity. In addition, seven of the shoulders that underwent previous subacromial decompression, experienced developed anterior-superior instability after hemiarthroplasty. ${ }^{75}$ In general, success of results was reported in about $67 \%$ of the cases. Williams and Rockwood reported 21 patients with arthritic shoulder along with defective rotator cuff who were treated by hemiarthroplasty. ${ }^{76}$ For a period of 4 years, $86 \%$ of patients had an acceptable result and their pain value dropped from 2.9 to 0.6 in the postoperation period. However, only 20 patients were painfree. It has been claimed that the weakening of results and significant prevalence of post-operation residual pain in these situations may have resulted from progressive bone troughs and acromial analysis). ${ }^{77}$

\section{Reverse Shoulder Arthroplasty}

This technique was lately created as a care method for glenohumeral arthritis to normalize advanced rotator cuff arthropathy. Standard shoulder replacement in the lack of rotator cuff performance is considered harmful due to loss of balanced coronal power. This is known as rocking-horse phenomenon which results in initial insufficiency in the glenoid loosening. ${ }^{78}$ Reverse total shoulder joint replacement is one type of shoulder joint replacement useful for patients with complete rotator cuff tear and severe weakness, rotator cuff tear of the shoulder muscle or arthropathy who had failure in earlier-used shoulder replacement surgeries. In this technique, the positions of hole and ball and socket joint of the whole shoulder are altered and thus, the patient can use the deltoid muscle instead of the rotator cuff muscle to lift the arm. These joints are designed in such a way that they have undergone changes compared to their original direction of rotation, and the lever arm across the glenoid is expanded as a result of loosening and loss of glenoid organs. Boileau et al altered these designs and increased the performance of the deltoid muscle by adjusting the center of rotation, reducing shear forces on the glenoid and putting deltoid muscle under tension by stretching of the arm. ${ }^{79}$ Though short-term results are encouraging, reverse shoulder arthroplasty is related to substantial morbidities and long-term results still continue to be particularly fixed. In one multifocal study, Gerber et al investigated the results of eighty artificial joints in 77 patients in less than 2 years. The mean constant score was improved from 23 to 66 and also, active angle grew from 73 to 138 . Reverse shoulder arthroplasty clinical outcome was about $91 \%$ within 5 years and about $75 \%$ within 7 years. However, the result reached lower than $30 \%$ within 8 years. ${ }^{81}$ The results of reverse shoulder arthroplasty are very poor when the posterior rotator cuff, especially minor fear muscle, malfunctions. ${ }^{82}$

\section{Discussion}

Rotator cuff tear is a common shoulder injury in elderly patients and its diagnosis in subsequent therapeutic interventions is very important. Multiple surgical techniques for the care of massive rotator cuff tears include simple debridement, tuberoplasty, joint mobility, tendon allograft and arthroplasty. ${ }^{37,78,80}$ Most studies have reported that the open surgery technique with the function of joint mobility or allograft is necessary for repair of all the disadvantages caused by massive rotator cuff tears. ${ }^{81,82}$ Criteria of massive rotator cuff tear treatment depend on the patient's condition and level of activity required following surgery. ${ }^{13}$ More studies have reported successful results without the repair of all the defects in patients with rotator cuff tears. ${ }^{83}$ Arthroscopic surgery is a technique useful in diagnosis and treatment. In recent decades, due to a better understanding of pathology and great developments in the field of technology, many improvements have been achieved in the short-term results of arthroscopic rotator cuff surgery, such that the results and findings have become better than those of open surgery in most cases. ${ }^{16,84}$ As mentioned in previous sections, arthroscopic techniques have advantages compared to open surgery including less surgical trauma, simple identification of the affected area, modification of the range of motion and ability to perform the surgery on an outpatient basis. However, the main problem with this technique is the prolonged period of acquiring skills and experience to perform this method. ${ }^{18}$ Also, this technique has other limits, so that some measures are necessary to be taken for better visibility in this method. The most important visibility confounding factor is bleeding that must be controlled carefully, otherwise, diagnosis of tear is carried out with difficulty. ${ }^{85}$ However, due to direct observation and high diagnosability, arthroscopy has been proposed as the gold standard for diagnosis of rotator cuff tears. ${ }^{86}$ In many studies and reports, the size of tear has been proposed as an open repair indication and it is believed that major massive tears cannot be treated with the arthroscopic method and open surgical procedures must be used for their treatment. However, 
with increasing surgeons' experience in arthroscopic repair and proper identification of the type and design of tear through arthroscopy, the desire for arthroscopic repair of such tears has been increased.

\section{Conclusion}

Massive rotator cuff tear might cause shoulder debilitating pain in most patients. This tear can require orthopedic surgeons to adopt difficult and complex therapies. Massive tear open repair is scientifically challenging and is correlated with a recurrence rate of the tear, which is lower in cases of smaller tears. For this purpose, accurate evaluation of patients to improve appropriate individualized care plans is highly necessary. The patient's history, physical inspection results, and imaging studies, when described in their records of performance objectives, can help to choose the best and most accurate treatment option. However, the existing evidence suggests that the majority of patients have experienced failure with non-surgical treatment methods and those chosen for open surgery, benefit surgical interventions. Arthroscopic debridement and minor repair can be measured for the elder and low-demand patients; however, attempts must be taken to repair rotator cuff tears in younger and symptomatic patients. In the event that full repair is possible from a technical perspective, a two-row suture may be helpful in terms of biomechanics and may assist to decrease the rate of recurrence of tears. High-demand patients compared to patients with massive rotator cuff tears may be prime applicants for a tendon transfer; yet, outcomes are contradictory and have only been calculated in small clinical groups. When arthritic changes are available in massive rotator cuff tear, shoulder joint replacement should be regarded. Also, hemiarthroplasty is a proper treatment approach for patients with symptomatic rotator cuff arthropathy.

\section{Ethical Considerations}

Not applicable.

\section{Conflict of Interests}

None to be declared.

\section{References}

1. Irrgang JJ, Lubowitz JH. Measuring Arthroscopic Outcome. Arthroscopy. 2008;24(6):718-722. doi:10.1016/j. arthro.2007.10.007

2. Park JY, Pandher DS, Moon GH, Yoo MJ, Lee ST. Comparison of surgical outcome in impingement syndrome with and without stiff shoulder. Indian J Orthop. 2008;42(2):182-187. doi:10.4103/0019-5413.40255

3. Holmes RE, Barfield WR, Woolf SK. Clinical evaluation of nonarthritic shoulder pain: Diagnosis and treatment. Phys Sportsmed. 2015;43(3):262-268. doi:10.1080/00913847.201 5.1005542

4. McCrory P. Campbell's operative orthopaedics, 10th ed (4 vols). Br J Sports Med. 2004;38(3):367-367.
5. Chung SW, Kim JY, Kim MH, Kim SH, Oh JH. Arthroscopic repair of massive rotator cuff tears: outcome and analysis of factors associated with healing failure or poor postoperative function. Am J Sports Med. 2013;41(7):16741683. doi:10.1177/0363546513485719

6. Moser M, Jablonski MV, Horodyski M, Wright TW. Functional outcome of surgically treated massive rotator cuff tears: a comparison of complete repair, partial repair, and debridement. Orthopedics. 2007;30(6):479-482.

7. Omid R, Lee B. Tendon transfers for irreparable rotator cuff tears. J Am Acad Orthop Surg. 2013;21(8):492-501. doi:10.5435/jaaos-21-08-492

8. Gerber C, Wirth SH, Farshad M. Treatment options for massive rotator cuff tears. J Shoulder Elbow Surg. 2011;20(2 Suppl):S20-29. doi:10.1016/j.jse.2010.11.028

9. Groh GI, Groh GM. Complications rates, reoperation rates, and the learning curve in reverse shoulder arthroplasty. $J$ Shoulder Elbow Surg. 2014;23(3):388-394. doi:10.1016/j. jse.2013.06.002

10. Mulieri P, Dunning P, Klein S, Pupello D, Frankle M. Reverse shoulder arthroplasty for the treatment of irreparable rotator cuff tear without glenohumeral arthritis. J Bone Joint Surg Am. 2010;92(15):2544-2556. doi:10.2106/ jbjs.i.00912

11. Zumstein MA, Pinedo M, Old J, Boileau P. Problems, complications, reoperations, and revisions in reverse total shoulder arthroplasty: a systematic review. J Shoulder Elbow Surg. 2011;20(1):146-157. doi:10.1016/j.jse.2010.08.001

12. Bishop J, Klepps S, Lo IK, Bird J, Gladstone JN, Flatow EL. Cuff integrity after arthroscopic versus open rotator cuff repair: a prospective study. J Shoulder Elbow Surg. 2006;15(3):290-299. doi:10.1016/j.jse.2005.09.017

13. Lee BG, Cho NS, Rhee YG. Results of arthroscopic decompression and tuberoplasty for irreparable massive rotator cuff tears. Arthroscopy. 2011;27(10):1341-1350. doi:10.1016/j.arthro.2011.06.016

14. Zingg PO, Jost B, Sukthankar A, Buhler M, Pfirrmann CW, Gerber C. Clinical and structural outcomes of nonoperative management of massive rotator cuff tears. J Bone Joint Surg Am. 2007;89(9):1928-1934. doi:10.2106/jbjs.f.01073

15. Williams GR Jr. Painful Shoulder After Surgery for Rotator Cuff Disease. J Am Acad Orthop Surg. 1997;5(2):97-108.

16. Gartsman GM, Roddey TS, Hammerman SM. Arthroscopic treatment of anterior-inferior glenohumeral instability. Two to five-year follow-up. J Bone Joint Surg Am. 2000;82a(7):991-1003.

17. Cole BJ, Romeo AA. Arthroscopic shoulder stabilization with suture anchors: technique, technology, and pitfalls. Clin Orthop Relat Res. 2001(390):17-30.

18. Liu SH, Henry MH. Anterior shoulder instability. Current review. Clin Orthop Relat Res. 1996(323):327-337.

19. Walch G, Boulahia A, Calderone S, Robinson AH. The 'dropping' and 'hornblower's' signs in evaluation of rotatorcuff tears. J Bone Joint Surg Br. 1998;80(4):624-628.

20. Elhassan B, Endres NK, Higgins LD, Warner JJ. Massive irreparable tendon tears of the rotator cuff: salvage options. Instr Course Lect. 2008;57:153-166.

21. Ainsworth R. Physiotherapy rehabilitation in patients with massive, irreparable rotator cuff tears. Musculoskeletal Care. 2006;4(3):140-151. doi:10.1002/msc.85

22. Bokor DJ, Hawkins RJ, Huckell GH, Angelo RL, 
Schickendantz MS. Results of nonoperative management of full-thickness tears of the rotator cuff. Clin Orthop Relat Res. 1993(294):103-110.

23. Peters KS, McCallum S, Briggs L, Murrell GA. A comparison of outcomes after arthroscopic repair of partial versus small or medium-sized full-thickness rotator cuff tears. $J$ Bone Joint Surg Am. 2012;94(12):1078-1085. doi:10.2106/ jbjs.j.00519

24. Hosseini-Tehrani A. Gray's anatomy (part I) joints of the body. Tehran: Nazar-Eshraghiye Publication; 1990.

25. Robin T. Ultrasound therapy for calcify tendonitis of the shoulder. Massachusetts: Medical Society; 2000.

26. Martin RL, Kelly BT, Philippon MJ. Evidence of validity for the hip outcome score. Arthroscopy. 2006;22(12):13041311. doi:10.1016/j.arthro.2006.07.027

27. Wright RW. Knee injury outcomes measures. J Am Acad Orthop Surg. 2009;17(1):31-39.

28. Cofield RH. Subscapular muscle transposition for repair of chronic rotator cuff tears. Surg Gynecol Obstet. 1982;154(5):667-672.

29. Rockwood CA Jr, Williams GR Jr, Burkhead WZ Jr. Debridement of degenerative, irreparable lesions of the rotator cuff. J Bone Joint Surg Am. 1995;77(6):857-866.

30. Montgomery TJ, Yerger B, Savoie FH 3rd. Management of rotator cuff tears: A comparison of arthroscopic debridement and surgical repair. J Shoulder Elbow Surg. 1994;3(2):70-78. doi:10.1016/s1058-2746(09)80113-4

31. Burkhart SS, Nottage WM, Ogilvie-Harris DJ, Kohn HS, Pachelli A. Partial repair of irreparable rotator cuff tears. Arthroscopy. 1994;10(4):363-370.

32. Gartsman GM. Massive, irreparable tears of the rotator cuff. Results of operative debridement and subacromial decompression. J Bone Joint Surg Am. 1997;79(5):715-721.

33. Neri BR, Chan KW, Kwon YW. Management of massive and irreparable rotator cuff tears. J Shoulder Elbow Surg. 2009;18(5):808-818. doi:10.1016/j.jse.2009.03.013

34. Warner JJ, McMahon PJ. The role of the long head of the biceps brachii in superior stability of the glenohumeral joint. J Bone Joint Surg Am. 1995;77(3):366-372.

35. Walch G, Edwards TB, Boulahia A, Nove-Josserand L, Neyton L, Szabo I. Arthroscopic tenotomy of the long head of the biceps in the treatment of rotator cuff tears: clinical and radiographic results of 307 cases. J Shoulder Elbow Surg. 2005;14(3):238-246. doi:10.1016/j.jse.2004.07.008

36. Bedi A, Dines J, Warren RF, Dines DM. Massive tears of the rotator cuff. J Bone Joint Surg Am. 2010;92(9):1894-1908. doi:10.2106/jbjs.i.01531

37. Burkhart SS. Reconciling the paradox of rotator cuff repair versus debridement: a unified biomechanical rationale for the treatment of rotator cuff tears. Arthroscopy. 1994;10(1):4-19.

38. Berth A, Neumann W, Awiszus F, Pap G. Massive rotator cuff tears: functional outcome after debridement or arthroscopic partial repair. J Orthop Traumatol. 2010;11(1):13-20. doi:10.1007/s10195-010-0084-0

39. Melillo AS, Savoie FH 3rd, Field LD. Massive rotator cuff tears: debridement versus repair. Orthop Clin North Am. 1997;28(1):117-124.

40. Zumstein MA, Jost B, Hempel J, Hodler J, Gerber C. The clinical and structural long-term results of open repair of massive tears of the rotator cuff. J Bone Joint Surg Am.
2008;90(11):2423-2431. doi:10.2106/jbjs.g.00677

41. Galatz LM, Ball CM, Teefey SA, Middleton WD, Yamaguchi $\mathrm{K}$. The outcome and repair integrity of completely arthroscopically repaired large and massive rotator cuff tears. J Bone Joint Surg Am. 2004;86-a(2):219-224.

42. Williams GR Jr, Rockwood CA Jr, Bigliani LU, Iannotti JP, Stanwood W. Rotator cuff tears: why do we repair them? J Bone Joint Surg Am. 2004;86-a(12):2764-2776.

43. Rokito AS, Zuckerman JD, Gallagher MA, Cuomo F. Strength after surgical repair of the rotator cuff. J Shoulder Elbow Surg. 1996;5(1):12-17.

44. Jost B, Pfirrmann CW, Gerber C, Switzerland Z. Clinical outcome after structural failure of rotator cuff repairs. $J$ Bone Joint Surg Am. 2000;82(3):304-314.

45. Burkhart SS, Barth JR, Richards DP, Zlatkin MB, Larsen M. Arthroscopic repair of massive rotator cuff tears with stage 3 and 4 fatty degeneration. Arthroscopy. 2007;23(4):347354. doi:10.1016/j.arthro.2006.12.012

46. Warner JP, Krushell RJ, Masquelet A, Gerber C. Anatomy and relationships of the suprascapular nerve: anatomical constraints to mobilization of the supraspinatus and infraspinatus muscles in the management of massive rotator-cuff tears. J Bone Joint Surg Am. 1992;74(1):36-45.

47. Hersche O, Gerber C. Passive tension in the supraspinatus musculotendinous unit after long-standing rupture of its tendon: a preliminary report. J Shoulder Elbow Surg. 1998;7(4):393-396.

48. Bigliani LU, Cordasco FA, McLlveen SJ, Musso ES. Operative repair of massive rotator cuff tears: Longterm results. J Shoulder Elbow Surg. 1992;1(3):120-130. doi:10.1016/1058-2746(92)90089-1

49. Lo IK, Burkhart SS. Arthroscopic repair of massive, contracted, immobile rotator cuff tears using single and double interval slides: technique and preliminary results. Arthroscopy. 2004;20(1):22-33. doi:10.1016/j. arthro.2003.11.013

50. Iagulli ND, Field LD, Hobgood ER, Ramsey JR, Savoie FH 3rd. Comparison of partial versus complete arthroscopic repair of massive rotator cuff tears. Am J Sports Med. 2012;40(5):1022-1026. doi:10.1177/0363546512438763

51. Fenlin JM Jr, Chase JM, Rushton SA, Frieman BG. Tuberoplasty: creation of an acromiohumeral articulation-a treatment option for massive, irreparable rotator cuff tears. J Shoulder Elbow Surg. 2002;11(2):136-142.

52. Scheibel M, Lichtenberg S, Habermeyer P. Reversed arthroscopic subacromial decompression for massive rotator cuff tears. J Shoulder Elbow Surg. 2004;13(3):272278. doi:10.1016/s1058274604000242

53. Park JG, Cho NS, Song JH, Baek JH, Rhee YG. Long-term outcome of tuberoplasty for irreparable massive rotator cuff tears: is tuberoplasty really applicable? J Shoulder Elbow Surg. 2016;25(2):224-231. doi:10.1016/j.jse.2015.07.025

54. Neviaser JS, Neviaser RJ, Neviaser TJ. The repair of chronic massive ruptures of the rotator cuff of the shoulder by use of a freeze-dried rotator cuff. J Bone Joint Surg Am. 1978;60(5):681-684.

55. Nasca RJ. The use of freeze-dried allografts in the management of global rotator cuff tears. Clin Orthop Relat Res. 1988(228):218-226.

56. Bond JL, Dopirak RM, Higgins J, Burns J, Snyder SJ. Arthroscopic replacement of massive, irreparable rotator 
cuff tears using a GraftJacket allograft: technique and preliminary results. Arthroscopy. 2008;24(4):403-409.e401. doi:10.1016/j.arthro.2007.07.033

57. Moore DR, Cain EL, Schwartz ML, Clancy WG Jr. Allograft reconstruction for massive, irreparable rotator cuff tears. Am J Sports Med. 2006;34(3):392-396. doi:10.1177/0363546505281237

58. Ito J, Morioka T. Surgical treatment for large and massive tears of the rotator cuff. Int Orthop. 2003;27(4):228-231. doi:10.1007/s00264-003-0459-4

59. Sano H, Mineta M, Kita A, Itoi E. Tendon patch grafting using the long head of the biceps for irreparable massive rotator cuff tears. J Orthop Sci. 2010;15(3):310-316. doi:10.1007/s00776-010-1453-5

60. Mori D, Funakoshi N, Yamashita F. Arthroscopic surgery of irreparable large or massive rotator cuff tears with low-grade fatty degeneration of the infraspinatus: patch autograft procedure versus partial repair procedure. Arthroscopy. 2013;29(12):1911-1921. doi:10.1016/j. arthro.2013.08.032

61. Badhe SP, Lawrence TM, Smith FD, Lunn PG. An assessment of porcine dermal xenograft as an augmentation graft in the treatment of extensive rotator cuff tears. J Shoulder Elbow Surg. 2008;17(1 Suppl):35s-39s. doi:10.1016/j. jse.2007.08.005

62. Iannotti JP, Codsi MJ, Kwon YW, Derwin K, Ciccone J, Brems JJ. Porcine small intestine submucosa augmentation of surgical repair of chronic two-tendon rotator cuff tears. A randomized, controlled trial. J Bone Joint Surg Am. 2006;88(6):1238-1244. doi:10.2106/jbjs.e.00524

63. Nada AN, Debnath UK, Robinson DA, Jordan C. Treatment of massive rotator-cuff tears with a polyester ligament (Dacron) augmentation: clinical outcome. J Bone Joint Surg Br. 2010;92(10):1397-1402. doi:10.1302/0301620x.92b10.24299

64. Hirooka A, Yoneda M, Wakaitani S, et al. Augmentation with a Gore-Tex patch for repair of large rotator cuff tears that cannot be sutured. J Orthop Sci. 2002;7(4):451-456. doi:10.1007/s007760200078

65. Visuri T, Kiviluoto O, Eskelin M. Carbon fiber for repair of the rotator cuff. A 4-year follow-up of 14 cases. Acta Orthop Scand. 1991;62(4):356-359.

66. Ricchetti ET, Aurora A, Iannotti JP, Derwin KA. Scaffold devices for rotator cuff repair. J Shoulder Elbow Surg. 2012;21(2):251-265. doi:10.1016/j.jse.2011.10.003

67. Aszmann OC, Dellon AL, Birely BT, McFarland EG. Innervation of the human shoulder joint and its implications for surgery. Clin Orthop Relat Res. 1996(330):202-207.

68. Kane TP, Rogers P, Hazelgrove J, Wimsey S, Harper GD. Pulsed radiofrequency applied to the suprascapular nerve in painful cuff tear arthropathy. J Shoulder Elbow Surg. 2008;17(3):436-440. doi:10.1016/j.jse.2007.10.007

69. Sluijter ME. The role of radiofrequency in failed back surgery patients. Curr Rev Pain. 2000;4(1):49-53.

70. Byrd D, Mackey S. Pulsed radiofrequency for chronic pain. Curr Pain Headache Rep. 2008;12(1):37-41.
71. Nizlan NM, Skirving AP, Campbell PT. Arthroscopic suprascapular neurectomy for the management of severe shoulder pain. J Shoulder Elbow Surg. 2009;18(2):245-250. doi:10.1016/j.jse.2008.09.001

72. Mihata T, McGarry MH, Pirolo JM, Kinoshita M, Lee TQ. Superior capsule reconstruction to restore superior stability in irreparable rotator cuff tears: a biomechanical cadaveric study. Am J Sports Med. 2012;40(10):2248-2255. doi:10.1177/0363546512456195

73. Mihata T, Lee TQ, Watanabe $C$, et al. Clinical results of arthroscopic superior capsule reconstruction for irreparable rotator cuff tears. Arthroscopy. 2013;29(3):459470. doi:10.1016/j.arthro.2012.10.022

74. Neer CS 2nd, Craig EV, Fukuda H. Cuff-tear arthropathy. J Bone Joint Surg Am. 1983;65(9):1232-1244.

75. Sanchez-Sotelo J, Cofield RH, Rowland CM. Shoulder hemiarthroplasty for glenohumeral arthritis associated with severe rotator cuff deficiency. J Bone Joint Surg Am. 2001;83-a(12):1814-1822.

76. Williams GR Jr, Rockwood CA Jr. Hemiarthroplasty in rotator cuff-deficient shoulders. J Shoulder Elbow Surg. 1996;5(5):362-367.

77. Zuckerman JD, Scott AJ, Gallagher MA. Hemiarthroplasty for cuff tear arthropathy. J Shoulder Elbow Surg. 2000;9(3):169-172.

78. Gerber C, Fuchs B, Hodler J. The results of repair of massive tears of the rotator cuff. J Bone Joint Surg Am. 2000;82(4):505-515.

79. Boileau P, Watkinson DJ, Hatzidakis AM, Balg F. Grammont reverse prosthesis: design, rationale, and biomechanics. $J$ Shoulder Elbow Surg. 2005;14(1 Suppl S):147S-161S.

80. Habermeyer P, Magosch P, Rudolph T, Lichtenberg S, Liem D. Transfer of the tendon of latissimus dorsi for the treatment of massive tears of the rotator cuff: a new singleincision technique. J Bone Joint Surg Br. 2006;88(2):208212. doi:10.1302/0301-620x.88b2.16830

81. Gerber C, Maquieira G, Espinosa N. Latissimus dorsi transfer for the treatment of irreparable rotator cuff tears. J Bone Joint Surg Am. 2006;88(1):113-120. doi:10.2106/ jbjs.e.00282

82. Gerber C, Rahm SA, Catanzaro S, Farshad M, Moor BK. Latissimus dorsi tendon transfer for treatment of irreparable posterosuperior rotator cuff tears: long-term results at a minimum follow-up of ten years. J Bone Joint Surg Am. 2013;95(21):1920-1926. doi:10.2106/jbjs.m.00122

83. Ellman H, Kay SP, Wirth M. Arthroscopic treatment of full-thickness rotator cuff tears: 2- to 7-year follow-up study. Arthroscopy. 1993;9(2):195-200.

84. Kim SH, Ha KI, Cho YB, Ryu BD, Oh I. Arthroscopic anterior stabilization of the shoulder: two to six-year follow-up. J Bone Joint Surg Am. 2003;85-a(8):1511-1518.

85. Burkhart SS, Lo IK, Brady PC. Burkhart's view of the shoulder: A cowboy's guide to advanced shoulder arthroscopy. LWW; 2006.

86. Miller MD, Cole BJD. Textbook of Arthroscopy. Gulf Professional Publishing; 2004. 